Article

\title{
Global Internet Data on the Interest in Antibiotics and Probiotics Generated by Google Trends
}

\author{
Mikołaj Kamiński ${ }^{1,2, *(0)}$, Igor Łoniewski ${ }^{3}\left(\mathbb{D}\right.$ and Wojciech Marlicz ${ }^{4}(\mathbb{D}$ \\ 1 Sanprobi Sp.z.o.o., 70-535 Szczecin, Poland \\ 2 Faculty of Medicine I, Poznan University of Medical Sciences, 60-780 Poznań, Poland \\ 3 Department of Biochemistry and Human Nutrition, Pomeranian Medical University, \\ 70-204 Szczecin, Poland; sanprobi@sanprobi.pl \\ 4 Department of Gastroenterology, Pomeranian Medical University, 70-204 Szczecin, Poland \\ * Correspondence: mikolaj.w.kaminski@gmail.com; Tel.: +48-516268563
}

Received: 2 August 2019; Accepted: 7 September 2019; Published: 12 September 2019

\begin{abstract}
Data from the Google search engine enables the assessment of Google users' interest in a specific topic. We analyzed the world trends in searches associated with the topics "antibiotics" and "probiotics" from January 2004 to June 2019, using Google Trends. We analyzed the yearly trends and seasonal variation. We performed an R-Spearman rank correlation analysis of the relative search volume (RSV) of the topics in 2015 with antibiotic consumption, health expenditure per capita, and the 2015 Human Development Index (HDI) of the country. The mean interest in the topic of antibiotics was equal to RSV $=57.5 \pm 17.9$, rising by $3.7 \mathrm{RSV} /$ year $(6.5 \% /$ year $)$, while that of probiotics was RSV $=14.1 \pm 7.9$, which rose by $1.7 \mathrm{RSV} /$ year $(12.1 \%)$. The seasonal amplitude of antibiotics was equal to RSV $=9.8$, while probiotics was RSV $=2.7$. The seasonal peaks for both topics were observed in the cold months. The RSV of probiotics, but not antibiotics, was associated with antibiotic consumption (Rs $=0.35 ; p<0.01)$, health expenditure ( $\mathrm{Rs}=0.41 ; p<0.001)$, and HDI $(\mathrm{Rs}=0.44 ; p<0.001)$. Google users' interest in antibiotic- and probiotic-related information increases from year to year, and peaks in cold months. The interest in probiotic-related information might be associated with antibiotic consumption, health expenditure, and the development status of the Google users' country.
\end{abstract}

Keywords: antibiotics; probiotics; Google Trends; Internet; antimicrobial resistance

\section{Introduction}

The data on the efficacy of probiotics is growing [1], and is generating interest among scientists, clinicians, and patients [2]. Currently, trial results may be quickly forwarded by social media to a wide audience of conscious consumers [3]. However, access to probiotics may be limited by regulatory agencies, and lack of knowledge on the beneficial properties of microbes in the local population [3]. The interest in probiotics may be seasonal. Some changes over time, which may be associated with the seasonal variation of gastrointestinal ailments, reveal a seasonal variation with a higher prevalence in autumn-winter $[4,5]$. Moreover, it is reported that the consumption of antibiotics peaks in winter and decreases in summer [6,7]. These seasonal variations may also be associated with an increase in the number of probiotic recommendations to relieve gastrointestinal complaints, or to restore gut microbiota. Indeed, we observed that the sales of probiotics are higher in colder than in warm months (Eoniewski and Marlicz-unpublished data). Up to $90 \%$ of Web users look for health-related information [8]. The Internet provides immediate access to an enormous amount of information. Beck et al. reported that $\sim 80 \%$ of users perceive the Web as a reliable source of information [9]. It is suggested that Internet traffic and areas of interest may mirror the health issues of the population [10]. The most popular search engine globally is Google. Some past studies have used Google data for the 
epidemiologic analysis of health-related issues [11-13]. We assume that Google data may reflect the changes in global interest in the terms and subjects related to antibiotics and probiotics. Therefore, we aimed to analyze, with a decomposition of time series data, to present the trends over time, seasonal variation, and irregular variation.

We aimed to investigate the interest (from 2004 to 2019) in the search terms "antibiotics", "antibiotic resistance", and "probiotics" among Google users worldwide.

\section{Methods}

We collected the data on 7 June 2019 using the Google tool, Google Trends (GT; https://trends. google.com/trends/). GT is an open-source tool that presents the relative search volume (RSV) of a specific phrase in a given country and period in the Google search engine. The data is available from January 2004 to the day of the query. Moreover, GT recognizes many "topics" that enables us to analyze the search volume of the same topic in all languages, for example, car and umbrella. It facilitates the easy comparison of the given terms across the world. RSV is an index of search volume adjusted to the number of Google users in a given geographical area. RSV ranges from 1-100, where the value of 100 indicates the peak of popularity ( $100 \%$ of popularity in the given period and location) and 0 the nadir $(<1 \%)$ [10]. GT also enables the comparison of more than one phrase or topic simultaneously. In this case, RSV $=100$ corresponds to the highest popularity of one of the compared terms. Initially, we chose the following topics: "antibiotics", "probiotics", "antimicrobial resistance", "prebiotics", and "synbiotics". To assess the ratio of interest in the topics, we calculated the ratio of the mean RSV of all of the topics to antibiotics. Moreover, we calculated a similar ratio of the number of findings in the PubMed search engine for all of the topics to antibiotics from 2004 to the date of collection. Because the interest in the topics may vary significantly, we included topics in the secondary analysis, with mean RSVs equal to or higher than 5. We compared the RSV of the chosen terms worldwide from January 2004 to the day of the collection. We excluded countries with low search volumes from the analysis. To ensure that the research is reproducible, we followed the recommendations of Nuti et al., and presented the search conditions in a modified checklist (Table S1) [10]. We analyzed the popularity of the selected topics using the Seasonal Decomposition of Time Series by Loess (Local Polynomial Regression Fitting), included in the ggseas package of R 3.6.1. (R Foundation, Vienna, Austria) [14]. The analysis decomposes time series data to present trends over time, including seasonal and irregular variations. The trend component reflects the long-term progression of the series, the seasonal variation presents the periodic changes of the time series, and the irregular variation presents the residuals of the time series after the other components are removed, representing random factors. All of the obtained components of the time series are presented in the same units as the primal time series, which, in our study, denotes RSV ( $y$-axis) over time ( $x$-axis). Most Google users live in the northern hemisphere, thus most of them experience their cold season from December to February. We chose three countries (Argentina, Australia, and South Africa) from the southern hemisphere to perform an additional time series decomposition, in order to reveal possible inverse RSV seasonal patterns related to the difference in months of the cold season. Additionally, we analyzed the time series decomposition of RSV of several countries with the highest relative interest for "probiotics". We illustrated the results using the ggplot and ggseas R packages [15]. We used the Seasonal Mann-Kendall test to detect the presence of a significant trend in the analyzed time trends $(\alpha=0.05)$ [16]. For significant trends, we performed a linear regression to estimate the slope expressed as changes in RSV per year, and the percentage of mean RSV per year. To determine the occurrence of the significant seasonal component, we fitted an exponential smoothing state space model with a Box-Cox transformation, autoregressive-moving average errors, and trend and seasonal components (TBATS) to the data [17]. In the case of a significant seasonal component, we calculated the seasonal amplitude by adding the absolute values of the highest and lowest monthly seasonal components, and expressed them as RSV and percentage of mean RSV. A $p$-value $<0.05$ was considered a significant difference. 
GT also presents a comparison of the chosen term in sub-regions. All of the chosen topics in a given sub-region added up to $100 \%$. We set countries as sub-regions. We did not illustrate the RSV from the sub-region comparison, and presented them in a grey color. The RSV was presented as a mean \pm standard deviation or percentage in the country analysis. Moreover, we used the R-Spearman rank correlation to search for associations between the RSV of the topics antibiotics and probiotics, with antibiotic consumption [18], antibiotic resistance (measured by the Drug Resistance Index) [19], inflation-adjusted healthcare expenditure per capita [20], and the Human Development Index (HDI) of the countries [21]. DRI represents the combined ability of antibiotics to treat infections, with the extent of their use in clinical circumstances, for a specific region [19]. Inflation-adjusted health expenditure per capita is a universal measure of the sum of the private and public health funding. The outcome is adjusted to the 2011 dollar. The Human Development Index is a combined index of life expectancy, education, and per capita income, which allows for comparing the development of the countries. Because the most recent and detailed information on antibiotics consumption and antibiotics resistance available are for 2015, we extracted the data for 2015 from GT for all of the countries with a significant RSV.

\section{Results}

In the initial analysis with all five topics, the mean RSV of antibiotics was equal to $57.6 \pm 18.0$, probiotic RSV $=14.1 \pm 7.9$, antimicrobial resistance RSV $=1.7 \pm 0.6$, prebiotic RSV $=1.3 \pm 0.7$, and synbiotics RSV $<1$ (which could not be accurately compared with the other topics). The ratio of Google users' interest was as follows: 4.1 (antibiotics/probiotic), 33.9 (antibiotics/antimicrobial resistance), and 44.3 (antibiotics/prebiotic). The ratios of PubMed findings were as follows: 16.9 (antibiotics/probiotic), 2.4 (antibiotics/antimicrobial resistance), and 56.6 (antibiotics/prebiotic). In the secondary analysis with two topics, antibiotics generated the highest interest in February 2019 (RSV =100), and the lowest in July 2006 (RSV = 33), with a mean RSV of $57.5 \pm 17.9$. Probiotics presented the highest interest in March 2019 (RSV = 33), and the lowest in fourteen months in 2004-2006 (RSV = 5), with a mean RSV of $14.1 \pm 7.9$ (Table 1). The visualization of the seasonal decomposition is presented in Figure 1.

The highest relative interest in probiotic was noted in Taiwan (probiotic/antibiotics; 58\%/42\%), Greece (45\%/55\%), Slovakia (36/64\%), Hong Kong (34\%/66\%), Canada (33\%/66\%), Singapore (33\%/67\%), Serbia (32\%/68\%), Bulgaria (31\%/69\%), Hungary (31\%/69\%), and the USA $(31 \% / 69 \%)$ (Figure 2), while the highest relative interest in antibiotics was observed in Egypt (5\%/95\%), Japan (5\%/95\%), Russia (5\%/95\%), Saudi Arabia (5\%/95\%), Vietnam (5\%/95\%), Kazakhstan (6\%/94\%), Venezuela (6\%/94\%), Argentina (8\%/92\%), Austria (9\%/91\%), Germany (9\%/91\%), and the Ukraine (9\%/91\%) (Figure S1).

We observed peaks in interest in the topics in June (Argentina-antibiotics and probiotics), August (Australia and South Africa-antibiotics), and September (Australia—probiotics), which corresponds to the local cold seasons (Table 1). Probiotics did not have any significant seasonal variation in South Africa. The time series decompositions of the topics for Argentina, Australia, and South Africa are presented in Supplementary S2A-S3C. We analyzed the time series decomposition of RSV of Taiwan, Greece, Canada, and the United States (Table S2 and Figure S3A-D).

We found significant associations between the RSVs of probiotic and antibiotic consumption, inflation-adjusted health expenditure per capita, and HDI (Table 2). There were no significant associations for antibiotics. 


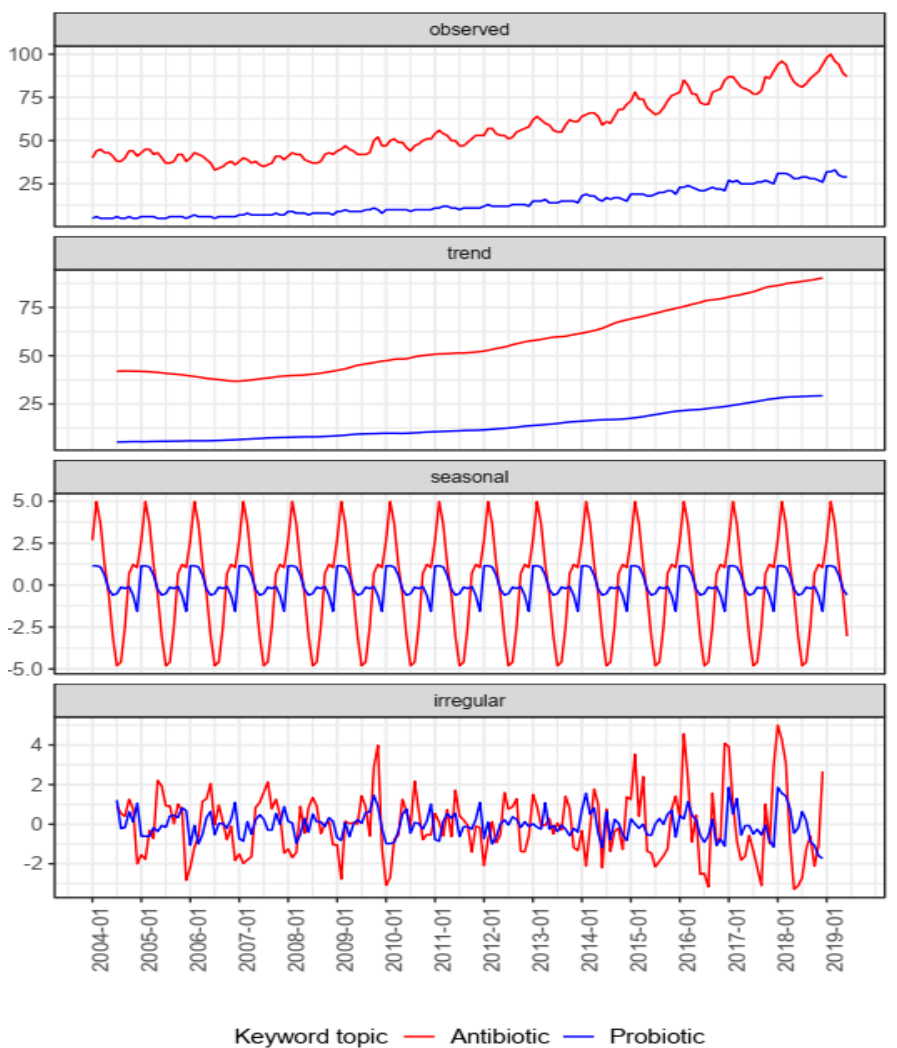

Figure 1. Relative search volume (RSV) of topics "antibiotic" and "probiotic" worldwide from January 2004 through June 2019, and the time series decomposition analysis by Loess. The $x$-axes of all of the mini-figures are the same periods. The $y$-axes are expressed in RSV. The mini-figure "observed" presents the course over time of the RSV of the topic. The mini-figure "trend" presents the trend over the analyzed period. The mini-figure "seasonal" presents the seasonal component of the time series "observed". The mini-figure "irregular" presents the variability, independent from the main trend and seasonal variation.

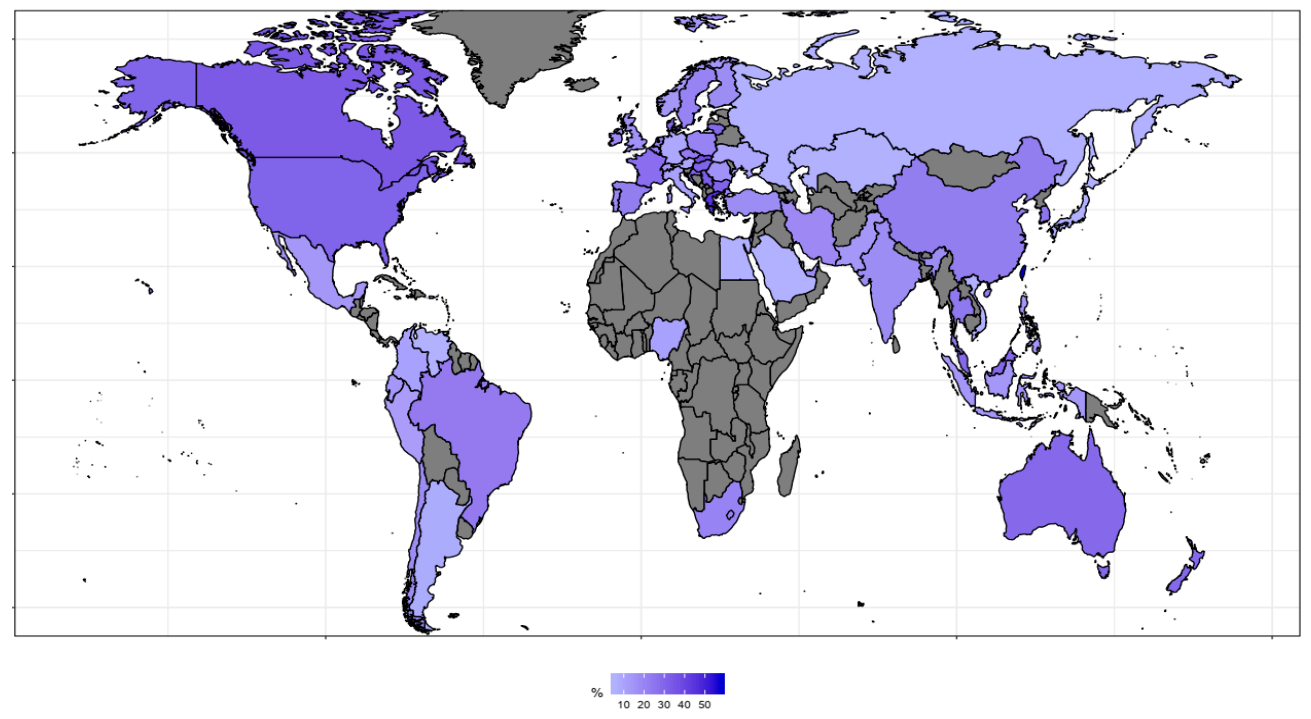

Figure 2. The relative interest of the topic "probiotics" worldwide. Gray color represents countries with low search volume, which were not included in the analysis. The list of the countries and values are available in Dataset in file "Figure 2 \& Figure S1.xls". 
Table 1. Time series analysis of the topics. Relative search volume (RSV) presented as mean \pm standard deviation. TBATS—exponential smoothing state space model with Box-Cox transformation, autoregressive-moving average errors, and trend and seasonal components. ${ }^{*} p<0.05,{ }^{* *} p<0.01,{ }^{* * *} p<0.01$

\begin{tabular}{|c|c|c|c|c|c|c|c|c|}
\hline Topic & Location & RSV & $\begin{array}{c}\text { Seasonal } \\
\text { Mann-Kendall } \\
\text { Test }\end{array}$ & Slope & $\begin{array}{l}\text { TBATS (Seasonality } \\
\text { Present, Period } \\
\text { [month]) }\end{array}$ & $\begin{array}{l}\text { Month with the } \\
\text { Lowest Seasonal } \\
\text { Component }\end{array}$ & $\begin{array}{l}\text { Month with the } \\
\text { Highest Seasonal } \\
\text { Component }\end{array}$ & $\begin{array}{l}\text { Seasonal } \\
\text { Component } \\
\text { Amplitude }\end{array}$ \\
\hline Antibiotics & Worldwide & $57.5 \pm 17.9$ & tau $=0.88^{* * *}$ & $\begin{array}{c}3.7 \mathrm{RSV} / \text { year } \\
\text { (6.5\%/year) }\end{array}$ & YES, 12 & July (-4.8 RSV) & February (5.0 RSV) & 9.8 RSV (17.0\%) \\
\hline Probiotic & Worldwide & $14.1 \pm 7.9$ & tau $=0.98^{* * *}$ & $\begin{array}{l}\text { 1.7 RSV/year } \\
\text { (12.1\%/year) }\end{array}$ & YES, 12 & December (-1.6 RSV) & February (1.1 RSV) & 2.7 RSV (19.1\%) \\
\hline Antibiotics & Argentina & $45.9 \pm 20.2$ & $\operatorname{tau}=0.77^{* * *}$ & $\begin{array}{c}3.9 \text { RSV/year } \\
(8.5 \% / \text { year })\end{array}$ & YES, 12 & February (-5.4 RSV) & June (5.7 RSV) & $\begin{array}{c}\text { 11.1 RSV } \\
(24.2 \%)\end{array}$ \\
\hline Probiotic & Argentina & $4.8 \pm 2.8$ & $\operatorname{tau}=0.32 * * *$ & $\begin{array}{c}0.2 \text { RSV/year } \\
(4.2 \% / \text { year })\end{array}$ & YES, 12 & January (-1.4 RSV) & June (1.0 RSV) & 2.4 RSV (50.0\%) \\
\hline Antibiotics & Australia & $54.5 \pm 18.9$ & $\operatorname{tau}=0.86^{* * *}$ & $\begin{array}{c}3.8 \text { RSV/year } \\
\text { (7.0\%/year) }\end{array}$ & YES, 12 & January (-9.3 RSV) & August (7.2 RSV) & $\begin{array}{c}\text { 16.5 RSV } \\
(30.3 \%)\end{array}$ \\
\hline Probiotic & Australia & $18.3 \pm 14.2$ & $\operatorname{tau}=0.88^{* * *}$ & $\begin{array}{c}2.9 \text { RSV/year } \\
(15.8 \%)\end{array}$ & YES, 12 & December (-3.9 RSV) & September (2.1 RSV) & 6.0 RSV (32.8\%) \\
\hline Antibiotics & South Africa & $53.7 \pm 17.1$ & $\operatorname{tau}=0.65^{* * *}$ & $\begin{array}{c}2.6 \text { RSV/year } \\
(4.9 \%)\end{array}$ & YES, 12 & December (-7.6 RSV) & August (6.5 RSV) & $\begin{array}{c}\text { 14.1 RSV } \\
(26.3 \%)\end{array}$ \\
\hline Probiotic & South Africa & $14.5 \pm 6.7$ & $\operatorname{tau}=0.38^{* * *}$ & $\begin{array}{c}0.5 \mathrm{RSV} / \text { year } \\
(3.4 \%)\end{array}$ & $\mathrm{NO},-$ & - & - & - \\
\hline
\end{tabular}

Table 2. R Spearman rank-correlation results.

\begin{tabular}{|c|c|c|c|c|c|}
\hline & RSV Antibiotics, 2015 & RSV Probiotic, 2015 & $\begin{array}{l}\text { Antibiotic Consumption, } \\
2015\end{array}$ & $\begin{array}{l}\text { Drug Resistance Index, } \\
\qquad 2015\end{array}$ & $\begin{array}{l}\text { Health Expenditure Per } \\
\text { Capita, } 2014\end{array}$ \\
\hline RSV probiotic, 2015 & Rs $=0.24 n=64$ & & & & \\
\hline Antibiotic Consumption, 2015 & $\mathrm{Rs}=0.14 n=65$ & Rs $=0.35^{* *} n=67$ & & & \\
\hline Drug Resistance Index, 2015 & Rs $=-0.13 n=40$ & $\mathrm{Rs}=-0.21 n=40$ & $\mathrm{Rs}=0.20 n=40$ & & \\
\hline $\begin{array}{l}\text { Inflation-Adjusted Health } \\
\text { Expenditure per Capita, } 2015\end{array}$ & Rs $=0.09 n=72$ & $\mathrm{Rs}=0.41^{* * *} n=61$ & $\mathrm{Rs}=0.27 * n=63$ & $\mathrm{Rs}=-0.84^{* * *} n=39$ & \\
\hline Human Development Index, 2015 & Rs $=0.09 n=73$ & Rs $=0.44{ }^{* * *} n=62$ & $\mathrm{Rs}=0.28 * n=63$ & Rs $=-0.84 * * * n=39$ & Rs $=0.95 * * * n=72$ \\
\hline
\end{tabular}




\section{Discussion}

We found that Google users' interest in antibiotics is on average four times higher than for probiotics. The interest in antimicrobial resistance, prebiotics, and synbiotics was marginal in comparison with antibiotics and probiotics. Interestingly, the number of findings generated in the PubMed search engine for the years 2004-2019 for the phrase antibiotics is $\sim 2.4$ times higher than for the phrase antimicrobial resistance, while in Google Trends, the ratio of RSV between both topics were equal, at $\sim 34$. These differences may reflect the lack of public interest in antimicrobial resistance and the need for increasing public awareness of this issue [22-24].

The global antibiotic consumption increased by 39\% between 2000 and 2015, and it is estimated that it will be up to $200 \%$ higher in 2030 than in 2015 [25]. The probiotics market is growing, and is speculated to grow 37\% globally from 2016 to 2020 [26]. The RSV of both antibiotics and probiotics is increasing over time. This might be associated with the growing consumption of both types of products. Additionally, the growing number of studies and the regulation of antibiotics and probiotics may generate public discourse. However, since 1990, no new classes of antibiotics were discovered. We found that the RSV of the topic probiotics increased relatively twice as fast as antibiotics. This may be related to the wide range of new beneficial effects of probiotics in the prevention of surgery-related complications [27], mental health [28], the cardiovascular system [29,30], insulin resistance [31], atopy [32], and many others. Furthermore, because of regulations, probiotics can be publicly advertised, while antibiotics cannot. It is also suggested that the community is aware of antibiotics, but have a little knowledge on their properties, risks and antimicrobial resistance [33].

Van Boeckel et al. reported that antibiotic consumption is at its highest during the cold season globally [6]. Moreover, the peaks of the number of antibiotic-related searches may be associated with the increased prevalence of infections in the cold season. Simultaneously, probiotics may be recommended to prevent antibiotic-associated diarrhea [34,35]. The fact that the nadir of both topics occurs in different months is also worth discussing. The decrease in the number of infections in summer may be related to the decrease in interest in the topic of antibiotics. Surprisingly, the nadir of the interest in the topic probiotics occurs in December, whereas in this month, both interest in and the consumption of antibiotics increases. We could not find any plausible explanation for this phenomenon. Another notable finding in the present study was the high variation in the interest in the topics antibiotics and probiotics among the countries. Interestingly, only in Taiwan was the RSV of the topic probiotics higher than antibiotics. The highest interest in probiotics was observed in several Balkans countries, the USA, and Canada, and minor highly developed countries in the Far East. Inversely, the regions with the highest interest in antibiotic-related information did not present a geographic pattern. The association between the RSV of the topic probiotics and antibiotic consumption might be caused by the recommendations of probiotics for the prevention of antibiotic-associated diarrhea, and to restore gut microbiota after antimicrobial treatment [34]. Google users from more developed countries generated more searches related to the topic probiotics. We speculate that it might be associated with better public awareness and the development of the probiotic market. We found that the RSV of the topic probiotics was positively associated with antibiotic consumption, health expenditure per capita, and HDI in 2015. This may be associated with the development of the local probiotics industry in the wealthier countries. Interestingly, the RSV of the topic antibiotics was not significantly associated with antibiotic consumption. The interest of antibiotics may not mirror the antibiotic consumption, as a result of the health policies limiting access to this type of drug. Therefore, the interest and will of a Google user cannot be easily converted into the purchase. Moreover, antibiotic consumption is highly dependent on the in-hospital use of antibiotics [36,37], we hypothesize that hospitalized patients may not generate Internet traffic related to the topic antibiotics. Antibiotics represent the old type of drug, and are used by clinicians all over the world. Therefore, the interest in the topic antibiotics may not correspond with health expenditure per capita and HDI. The DRI was not significantly associated with interest in antibiotics. It may be explained by no relation between the RSV 
of the topic and antibiotics consumption, which could potentially generate an increase in antibiotic resistance. However, the analysis was performed only for 2015 which limits the conclusions.

This study was the first of its kind to explore the interest of Internet users in antibiotics, probiotics, prebiotics, synbiotics, and antimicrobial resistance. We followed the recommendation of Nuti et al., so as to ensure the reproducibility of the study [10]. We found that the users' interest corresponds to the epidemiological data on antibiotic consumption. Moreover, we found that the topic antimicrobial resistance may be underrepresented in Internet discourse. Finally, we found that the interest in probiotics-related information varied among the countries, but is positively associated with the development status of the country, health expenditure, and antibiotic consumption.

The authors acknowledge several limitations of this study. Firstly, GT only enables the estimation of RSV; it is not possible to use GT to assess a precise number of queries. Secondly, using GT is the most credible for relatively common phenomena, which are resistant to media clamour [38]. The RSV of the topics could be dependent on media attention, and this could be the reason for the high amplitude of the irregular component in the time series of the topics in Argentina, South Africa, and Australia. Thirdly, the results are limited because of the low search volume in many, mostly African, countries. Fourthly, because of limited data on antibiotic consumption, we could only perform the R Spearman correlation test for 2015. Finally, using GT may provide insight into an under-researched epidemiological pattern, but the observations should be verified with real-world research.

Taken together, our research reveals that Google users' interest in antibiotic- and probiotic-related information increases from year to year, and peaks in cold months. Internet traffic related to the topic probiotics doubled in comparison with the topic antibiotics. The interest in probiotic-related information is associated with antibiotic consumption, health expenditure, and the development status of the Google users' country.

Supplementary Materials: The following are available online at http://www.mdpi.com/2079-6382/8/3/147/s1: Table S1: Checklist for Documentation of Google Trends research; Table S2: Additional time series analysis of the topics. Figure S1: The relative interest of the topic "antibiotics" worldwide. Gray color represents countries with a low search volume, which were not included in analysis; Figure S2A: Relative search volume (RSV) of topics "antibiotic" and "probiotic" in Argentina from January 2004 through June 2019, and time series decomposition analysis by Loess. Figure S2B: Relative search volume (RSV) of topics "antibiotic" and "probiotic" in Australia from January 2004 through June 2019, and time series decomposition analysis by Loess. Figure S2C: Relative search volume (RSV) of topics "antibiotic" and "probiotic" in South Africa from January 2004 through June 2019, and time series decomposition analysis by Loess. Figure S3A: Relative search volume (RSV) of topics "antibiotic" and "probiotic" in Canada from January 2004 through June 2019, and time series decomposition analysis by Loess. Figure S3B: Relative search volume (RSV) of topics "antibiotic" and "probiotic" in Greece from January 2004 through June 2019, and the time series decomposition analysis by Loess. Figure S3C: Relative search volume (RSV) of topics "antibiotic" and "probiotic" in Taiwan from January 2004 through June 2019, and the time series decomposition analysis by Loess. Figure S3D: Relative search volume (RSV) of topics "antibiotic" and "probiotic" in The United States from January 2004 through June 2019, and the time series decomposition analysis by Loess.

Author Contributions: Conceptualization, M.K. and I.Ł.; data curation, M.K.; formal analysis, M.K.; investigation, M.K.; methodology, M.K.; project administration, M.K.; resources, M.K.; software, M.K.; supervision, I.E. and W.M.; visualization, M.K.; writing (original draft), M.K.; writing (review and editing), M.K., I.Ł., and W.M.

Funding: This research received no external funding.

Acknowledgments: We would like to thank Editage (www.editage.com) for the English language editing.

Conflicts of Interest: I.E. and W.M. are the foundation shareholders of Sanprobi, the manufacturer and distributor of the probiotics. M.K. received remuneration from this company, and the content of this study was not subjected to any constraints by this company.

\section{References}

1. Wilkins, T.; Sequoia, J. Probiotics for Gastrointestinal Conditions: A Summary of the Evidence. Am. Fam. Physician 2017, 96, 170-178. [PubMed]

2. Venema, K. Foreword-There is still tremendous interest in probiotics and prebiotics. Benef. Microbes 2015, 6, 1-2. [CrossRef] [PubMed] 
3. Reid, G.; Kort, R.; Alvarez, S.; Bourdet-Sicard, R.; Benoît, V.; Cunningham, M.; Saulnier, D.; Vlieg, J.V.H.; Verstraelen, H.; Sybesma, W. Expanding the reach of probiotics through social enterprises. Benef. Microbes 2018, 9, 707-715. [CrossRef] [PubMed]

4. Piotrowicz, G.; Stępień, B.; Rydzewska, G. Socio-demographic characteristics of patients with diagnosed functional dyspepsia. Gastroenterol. Rev. 2013, 8, 354-365. [CrossRef] [PubMed]

5. Chen, K.Y.; Lin, H.C.; Lou, H.Y.; Lee, S.H. Seasonal Variation in the Incidence of Gastroesophageal Reflux Disease. Am. J. Med. Sci. 2009, 338, 453-458. [CrossRef] [PubMed]

6. Van Boeckel, T.P.; Gandra, S.; Ashok, A.; Caudron, Q.; Grenfell, B.T.; Levin, S.A.; Laxminarayan, R. Global antibiotic consumption 2000 to 2010: An analysis of national pharmaceutical sales data. Lancet Infect. Dis. 2014, 14, 742-750. [CrossRef]

7. Elseviers, M.M.; Ferech, M.; Vander Stichele, R.H.; Goossens, H.; ESAC Project Group. Antibiotic use in ambulatory care in Europe (ESAC data 1997-2002): Trends, regional differences and seasonal fluctuations, Pharmacoepidem. Drug Safe 2007, 16, 115-123. [CrossRef] [PubMed]

8. McDaid, D.; Park, A.L. Online Health: Untangling the Web. 2010. Available online: https://www.bupa. com.au/staticfiles/Bupa/HealthAndWellness/MediaFiles/PDF/LSE_Report_Online_Health.pdf (accessed on 14 June 2019).

9. Singh, P.; Van Mierlo, T.; Beck, F.; Richard, J.B.; Nguyen-Thanh, V.; Montagni, I.; Parizot, I.; Renahy, E. Use of the Internet as a Health Information Resource among French Young Adults: Results from a Nationally Representative Survey. J. Med. Internet Res. 2014, 16, e128.

10. Nuti, S.V.; Wayda, B.; Ranasinghe, I.; Wang, S.; Dreyer, R.P.; Chen, S.I.; Murugiah, K. The Use of Google Trends in Health Care Research: A Systematic Review. PLoS ONE 2014, 9, e109583. [CrossRef]

11. Ginsberg, J.; Mohebbi, M.H.; Patel, R.S.; Brammer, L.; Smolinski, M.S.; Brilliant, L. Detecting influenza epidemics using search engine query data. Nature 2008, 457, 1012. [CrossRef]

12. Zink, A.; Schuster, B.; Rüth, M.; Pereira, M.P.; Philipp-Dormston, W.G.; Biedermann, T.; Ständer, S. Medical needs and major complaints related to pruritus in Germany: A 4-year retrospective analysis using Google AdWords Keyword Planner. J. Eur. Acad. Dermatol. Venereol. 2019, 33, 151-156. [CrossRef] [PubMed]

13. Boehm, A.; Pizzini, A.; Sonnweber, T.; Loeffler-Ragg, J.; Lamina, C.; Weiss, G.; Tancevski, I. Assessing global COPD awareness with Google Trends. Eur. Respir. J. 2019, 1900351. [CrossRef] [PubMed]

14. Ellis, P.; Sax, C. Ggseas: "Stats" for Seasonal Adjustment on the Fly with "Ggplot2". 2018. Available online: https://cran.r-project.org/web/packages/ggseas/index.html (accessed on 6 June 2019).

15. Wickham, H. Ggplot2: Elegant Graphics for Data Analysis, 2nd ed.; Springer: Cham, Switzerland, 2016.

16. McLeod, A.I. Kendall Rank Correlation and Mann-Kendall Trend Test. 2011. Available online: https: //cran.r-project.org/web/packages/Kendall/Kendall.pdf (accessed on 13 June 2019).

17. Hyndman, R. Forecasting Functions for Time Series and Linear Models. 2019. Available online: https: //cran.r-project.org/web/packages/forecast/forecast.pdf (accessed on 13 June 2019).

18. The Center for Disease Dynamics Economics \& Policy. ResistanceMap: Antibiotic Resistance. 2018. Available online: https://resistancemap.cddep.org/AntibioticUse.php (accessed on 27 June 2019).

19. The Center for Disease Dynamics Economics \& Policy. Drug Resistance Index Map. 2018. Available online: https://resistancemap.cddep.org/DRI.php (accessed on 27 June 2019).

20. World Health Organization. Global Health Expenditure Database. Available online: http://apps.who.int/nha/ database/Select/Indicators/en (accessed on 27 June 2019).

21. United Nations Development Programme. Human Development Reports. Available online: http://hdr.undp. org/en/data (accessed on 27 June 2019).

22. Castro-Sánchez, E.; Moore, L.S.P.; Husson, F.; Holmes, A.H. What are the factors driving antimicrobial resistance? Perspectives from a public event in London, England. BMC Infect. Dis. 2016, 16, 465. [CrossRef] [PubMed]

23. Davis, M.; Whittaker, A.; Lindgren, M.; Djerf-Pierre, M.; Manderson, L.; Flowers, P. Understanding media publics and the antimicrobial resistance crisis. Glob. Public Health 2018, 13, 1158-1168. [CrossRef] [PubMed]

24. Edwards, S.E.; Morel, C.M.; Busse, R.; Harbarth, S. Combatting Antibiotic Resistance Together: How Can We Enlist the Help of Industry? Antibiotics 2018, 7, 111. [CrossRef] [PubMed]

25. Klein, E.Y.; Van Boeckel, T.P.; Martinez, E.M.; Pant, S.; Gandra, S.; Levin, S.A.; Goossens, H.; Laxminarayan, R. Global increase and geographic convergence in antibiotic consumption between 2000 and 2015. Proc. Natl. Acad. Sci. USA 2018, 115, E3463-E3470. [CrossRef] [PubMed] 
26. Feldman, M. The New Market Profile of Probiotics Consumption, Natural Products Insider. 2016. Available online: https://www.naturalproductsinsider.com/digestive-health/new-market-profile-probioticsconsumption (accessed on 12 July 2019).

27. Skonieczna-Żydecka, K.; Kaczmarczyk, M.; Łoniewski, I.; Lara, L.F.; Koulaouzidis, A.; Misera, A.; Maciejewska, D.; Marlicz, W. A Systematic Review, Meta-Analysis, and Meta-Regression Evaluating the Efficacy and Mechanisms of Action of Probiotics and Synbiotics in the Prevention of Surgical Site Infections and Surgery-Related Complications. J. Clin. Med. 2018, 7, 556. [CrossRef]

28. Skonieczna-Żydecka, K.; Marlicz, W.; Misera, A.; Koulaouzidis, A.; Łoniewski, I. Microbiome-The Missing Link in the Gut-Brain Axis: Focus on Its Role in Gastrointestinal and Mental Health. J. Clin. Med. 2018, 7, 521. [CrossRef]

29. Aoyagi, Y.; Park, S.; Matsubara, S.; Honda, Y.; Amamoto, R.; Kushiro, A.; Miyazaki, K.; Shephard, R. Habitual intake of fermented milk products containing Lactobacillus casei strain Shirota and a reduced risk of hypertension in older people. Benef. Microbes 2017, 8, 23-29. [CrossRef]

30. Szulińska, M.; Łoniewski, I.; Skrypnik, K.; Sobieska, M.; Korybalska, K.; Suliburska, J.; Bogdański, P. Multispecies Probiotic Supplementation Favorably Affects Vascular Function and Reduces Arterial Stiffness in Obese Postmenopausal Women-A 12-Week Placebo-Controlled and Randomized Clinical Study. Nutrients 2018, 10, 1672. [CrossRef]

31. Li, X.; Wang, E.; Yin, B.; Fang, D.; Chen, P.; Wang, G.; Zhao, J.; Zhang, H.; Chen, W. Effects of Lactobacillus casei CCFM419 on insulin resistance and gut microbiota in type 2 diabetic mice. Benef. Microbes 2017, 8, 421-432. [CrossRef] [PubMed]

32. Prakoeswa, C.; Herwanto, N.; Prameswari, R.; Astari, L.; Sawitri, S.; Hidayati, A.; Indramaya, D.; Kusumowidagdo, E.; Surono, I. Lactobacillus plantarum IS-10506 supplementation reduced SCORAD in children with atopic dermatitis. Benef. Microbes 2017, 8, 833-840. [CrossRef] [PubMed]

33. A Scientific Roadmap for Antibiotic Discovery: A Sustained and Robust Pipeline of new Antibacterial Drugs and Therapies is Critical to Preserve Public Health. 2016. Available online: https://www.pewtrusts. org/en/research-and-analysis/reports/2016/05/a-scientific-roadmap-for-antibiotic-discovery (accessed on 3 September 2019).

34. Hempel, S.; Newberry, S.J.; Maher, A.R.; Wang, Z.; Miles, J.N.V.; Shanman, R.; Johnsen, B.; Shekelle, P.G. Probiotics for the prevention and treatment of antibiotic-associated diarrhea: A systematic review and meta-analysis. JAMA 2012, 307, 1959-1969. [CrossRef] [PubMed]

35. Blaabjerg, S.; Artzi, D.; Aabenhus, R. Probiotics for the Prevention of Antibiotic-Associated Diarrhea in Outpatients-A Systematic Review and Meta-Analysis. Antibiotics 2017, 6, 21. [CrossRef] [PubMed]

36. Srinivasan, A.; Baggs, J.; Fridkin, S.K.; Pollack, L.A.; Jernigan, J.A. Estimating National Trends in Inpatient Antibiotic Use among US Hospitals from 2006 to 2012. JAMA Intern. Med. 2016, 176, 1639-1648.

37. Oza, A.; Donohue, F.; Johnson, H.; Cunney, R. Risk-adjusted antibiotic consumption in 34 public acute hospitals in Ireland, 2006 to 2014. EuroSurveillance 2016, 21, 30312. [CrossRef] [PubMed]

38. Cervellin, G.; Comelli, I.; Lippi, G. Is Google Trends a reliable tool for digital epidemiology? Insights from different clinical settings. J. Epidemiol. Glob. Health 2017, 7, 185-189. [CrossRef] [PubMed]

(C) 2019 by the authors. Licensee MDPI, Basel, Switzerland. This article is an open access article distributed under the terms and conditions of the Creative Commons Attribution (CC BY) license (http://creativecommons.org/licenses/by/4.0/). 